\title{
Bioavailability Studies of Acetaminophen and Nitrofurantoin
}

K. S. Albert, Ph.D., A. J. SEDMAN, P. WILKINSON, R. G. STOLL,* Ph.D., W. J. MURRAY,t M.D., Ph.D., and J. G. WAGNER, Ph.D. Ann Arbor, Mich.

$\mathrm{T}_{\mathrm{t}}^{\mathrm{s}}$ HE effects of dosage form variables on 1 therapeutic efficacy and/or bioavailability of drugs are well documented. ${ }^{1}$ Usually, these effects will be manifest principally in differences in rate of absorption and/or differences in efficiency of absorption. Since a formulation which releases a drug slowly over an extended time could have the same bioavailability as a formulation with a more rapid rate of absorption, it is important to consider both rate and extent of absorption as criteria for assessing therapeutic equivalency.

Gwilt et al. ${ }^{2}$ noted differences in blood and plasma levels of acetaminophen after administering $1 \mathrm{Gm}$ of drug as whole tablets (eight different manufacturers), as crushed tablets (one manufacturer), and as a tablet containing sorbitol. However, his comparisons were made at a single sampling time (45 minutes after administration). McGilveray et al. $^{3}$ compared efficiencies and rates of absorption of eight

From the College of Pharmacy and Upjohn Center for Clinical Pharmacology, University of Michigan, Ann Arbor, Mich.

These studies were supported by a contract from the R. P. Scherer Corporation.

* Present address: Clinical Bioavailability Unit, The Upjohn Company, Kalamazoo, Mich.

† Present address: Department of Anesthesiology, Duke University Medical Center, Durham, N.C.

264 lots of tablets, one elixir, and an aqueous solution of acetaminophen in ten subjects each receiving 1-Gm doses weekly for ten weeks. No differences in rate or extent of availability were noted among formulations from either blood level or urinary excretion data after monitoring free drug as well as total levels.

Mattok et al. ${ }^{4}$ observed the sensitivity of the bioavailability of nitrofurantoin to changes in formulation of the drug. One hundred-milligram doses of nitrofurantoin were administered to 30 subjects in the form of commercially available tablets from one manufacturer. Bioavailabilities based on urinary data were expressed as per cent of that obtained with a control suspension as well as the per cent of the innovator's product. An in vivo-in vitro comparison was attempted, but results indicated that the dissolution tests did not accurately reflect in vivo absorption.

In a recent study, Hom and Miskel ${ }^{5}$ demonstrated enhanced in vitro rates of dissolution for a series of chemically and pharmacologically different drugs when formulated in special soft gelatin capsules compared to commercially available tablets. Since in vitro dissolution rate reflects the bioavailability potential of a drug in a dosage form, two human studies were undertaken to compare plasma levels and urinary excretion of the drugs acetamino-

The Journal of Clinical Pharmacology 
BIOAVAILABILITY OF ACETAMINOPHEN AND NITROFURANTOIN

TABLE I

Treatment Schedules*

\begin{tabular}{cccccc}
\hline \multirow{2}{*}{ Study } & Subject no. & Group & I & II \\
\hline \multirow{2}{*}{ Acetaminophen } & $1,2,3,4,5$, & 1 & A & B \\
& $6,7,8,9,10$ & 2 & B & A \\
Nitrofurantoin & $1,2,3,4,5$, & 1 & A & B \\
& $6,7,8,9,10$ & 2 & B & A \\
\hline
\end{tabular}

* The studies were separated by about 6 months; phases were separated by a 1-week period. For acetaminophen, treatment $A$ is the soft gelatin capsule (R. P. Scherer Corp.), treatment $B$ is the commercial tablet (Tylenol, McNeil). For nitrofurantoin, treatment $A$ is the soft gelatin capsule (R. P. Scherer Corp.), treatment $\mathbf{B}$ is the commercial tablet (Furadantin, Eaton).

phen and nitrofurantoin. Single oral doses given as commercially available tablets and as specially formulated soft gelatin capsules were used in these two studies. (Poloxamer 212 was the surfactant in the acetaminophen formulation, while Poloxamer 212 and Poloxamer 234, in a ratio of 4 to 1 , were used as bases in the nitrofurantoin capsule.)

\section{Materials and Methods}

Ten healthy male volunteers chosen for each study were selected based upon criteria previously described. ${ }^{6}$ The studies were performed using a Latin-square crossover design with two groups of five subjects possessing similar average body weights. The study conditions were essentially as described previously, ${ }^{6}$ with the following modifications.

Acetaminophen. On the mornings acetaminophen was administered, each subject drank $6 \mathrm{fl}$ oz of water within the first hour after arising and $6 \mathrm{fl} \mathrm{oz}$ of water when the medication was administered. On each phase of the two-way crossover, each subject took two 325-mg capsules (treatment A) or two 325-mg tablets (treatment B), swallowing the prepara- tions intact. (Treatment $A$ was the soft gelatin capsule, R. P. Scherer Corp.; treatment B was Tylenol tablets, McNeil Laboratories.) Blood, $10 \mathrm{ml}$, was withdrawn from a forearm vein prior to dosing and at $10,20,30,40,60,120,240,360,480$, and 720 minutes after dosing. Zero- to 24hour urine specimens were also obtained and stored in plastic bottles containing 1 $\mathrm{ml}$ toluene. After collection, the volume was measured and the urine was quickfrozen and kept in a frozen state until just prior to assay. Plasma and urine samples were assayed by the GLC procedure described by Kostenbauder. ${ }^{7}$

Nitrofurantoin. On the mornings nitrofurantoin was administered, each subject drank $6 \mathrm{fl}$ oz of water at $-2,-1,0,+1$, $+2,+3,+4$, and +5 hours, where 0 is the time of dosing. On each phase of the two-way study, each subject ingested one capsule (treatment A) or a tablet containing $100 \mathrm{mg}$ nitrofurantion (treatment $\mathrm{B}$ ). (Treatment $A$ was the soft gelatin capsule, R. P. Scherer Corp.; treatment B here was Furadantin tablets, Eaton Laboratories.) Blood, $10 \mathrm{ml}$, was withdrawn from a forearm vein prior to dosing and at 10 , $20,30,40,60,120$, and 240 minutes after 
ALBERT ET AL.

TABLE II

Summary of Average Plasma Concentrations and 24-Hour Urinary Excretion of Acetaminophen in Ten Normal Subjects Following a Single 650-mg Oral Dose

\begin{tabular}{|c|c|c|c|c|}
\hline & \multicolumn{2}{|c|}{$\begin{array}{c}\text { Average plasma concentration } \\
(\mu \mathrm{g} / \mathrm{ml})\end{array}$} & \multirow{2}{*}{$\begin{array}{c}\text { Significance } \\
\text { level of difference } \\
\text { between treatment } \\
\text { averages from ANOVA* }\end{array}$} & \multirow{2}{*}{$\begin{array}{l}\text { C. V. } \\
\text { (\%) from } \\
\text { residual } \\
\text { mean square }\end{array}$} \\
\hline & Treatment $\mathbf{A}$ & Treatment B & & \\
\hline \multicolumn{5}{|l|}{ Time (min) } \\
\hline 10 & 0.02 & 2.06 & sig. $(0.05>P>0.025)$ & 160 \\
\hline 20 & 1.73 & 4.24 & n.s. $(0.25>P>0.10)$ & 135 \\
\hline 30 & 2.38 & 4.91 & n.s. $(0.10>P>0.05)$ & 83.4 \\
\hline 40 & 3.26 & 5.69 & sig. $(0.025>P>0.01)$ & 42.7 \\
\hline 60 & 4.82 & 6.36 & sig. $(0.05>P>0.025)$ & 24.6 \\
\hline 120 & 5.36 & 4.94 & n.s. $(P>0.25)$ & 23.0 \\
\hline 240 & 3.13 & 2.54 & sig. $(0.01>P>0.005)$ & 13.0 \\
\hline 360 & 1.84 & 1.50 & sig. $(0.025>P>0.01)$ & 13.8 \\
\hline 480 & 1.22 & 0.83 & sig. $(0.005>P>0.001)$ & 21.7 \\
\hline 720 & 0.52 & 0.34 & sig. $(0.005>P>0.001)$ & 22.6 \\
\hline Peak $(\mu \mathrm{g} / \mathrm{ml})$ & 6.93 & 7.72 & n.s. $(P>0.25)$ & 28.6 \\
\hline Time of peak ( $\min )$ & 84.0 & 58.0 & n.s. $(0.10>P>0.05)$ & 39.3 \\
\hline Area $(0-480 \mathrm{~min})$ & 1453 & 1431 & n.s. $(P>0.25)$ & 11.1 \\
\hline Area $(0-720 \mathrm{~min})$ & 1654 & 1572 & n.s. $(P>0.25)$ & 11.1 \\
\hline \multicolumn{5}{|c|}{$\begin{array}{l}\text { Amount of unchanged } \\
\text { acetaminophen excreted } \\
\text { in urine in } 24 \text { hours } \\
(\mathrm{mg})\end{array}$} \\
\hline
\end{tabular}

* ANOVA=Analysis of variance for crossover design.

TABLE III

Summary of Average Plasma Concentrations of Nitrofurantoin in Ten Normal Subjects Following a Single 100-mg Oral Dose

\begin{tabular}{|c|c|c|c|c|}
\hline & \multicolumn{2}{|c|}{$\begin{array}{l}\text { Average plasma concentration } \\
(\mu \mathrm{g} / \mathrm{ml})\end{array}$} & \multirow{2}{*}{$\begin{array}{c}\text { Significance } \\
\text { level of difference } \\
\text { between treatment } \\
\text { averages from ANOVA }\end{array}$} & \multirow{2}{*}{$\begin{array}{l}\text { C.V. }(\%) \\
\text { from residual } \\
\text { mean square }\end{array}$} \\
\hline & Treatment $\mathbf{A}$ & Treatment $\mathrm{B}$ & & \\
\hline \multicolumn{5}{|l|}{ Time (min) } \\
\hline 10 & 0.231 & 0.0644 & n.s. $(0.10>P>0.05)$ & 131. \\
\hline 20 & 0.364 & 0.132 & sig. $(0.025>P>0.01)$ & 71.1 \\
\hline 30 & 0.645 & 0.347 & n.s. $(0.25>P>0.10)$ & 82.5 \\
\hline 40 & 0.836 & 0.315 & sig. $(0.05>P>0.025)$ & 82.1 \\
\hline 60 & 0.950 & 0.355 & sig. $(0.01>P>0.005)$ & 59.0 \\
\hline 120 & 1.08 & 0.799 & n.s. $(P>0.25)$ & 71.6 \\
\hline 240 & 0.619 & 0.500 & n.s. $(P>0.25)$ & 90.0 \\
\hline Peak $(\mu \mathrm{g} / \mathrm{ml})$ & 1.47 & 0.986 & sig. $(0.025>P>0.001)$ & 31.4 \\
\hline Area $(0-240 \mathrm{~min})$ & 197. & 126. & n.s. $(0.10>P>0.05)^{*}$ & 48.0 \\
\hline
\end{tabular}

* Same results obtained by paired $t$-test also. 


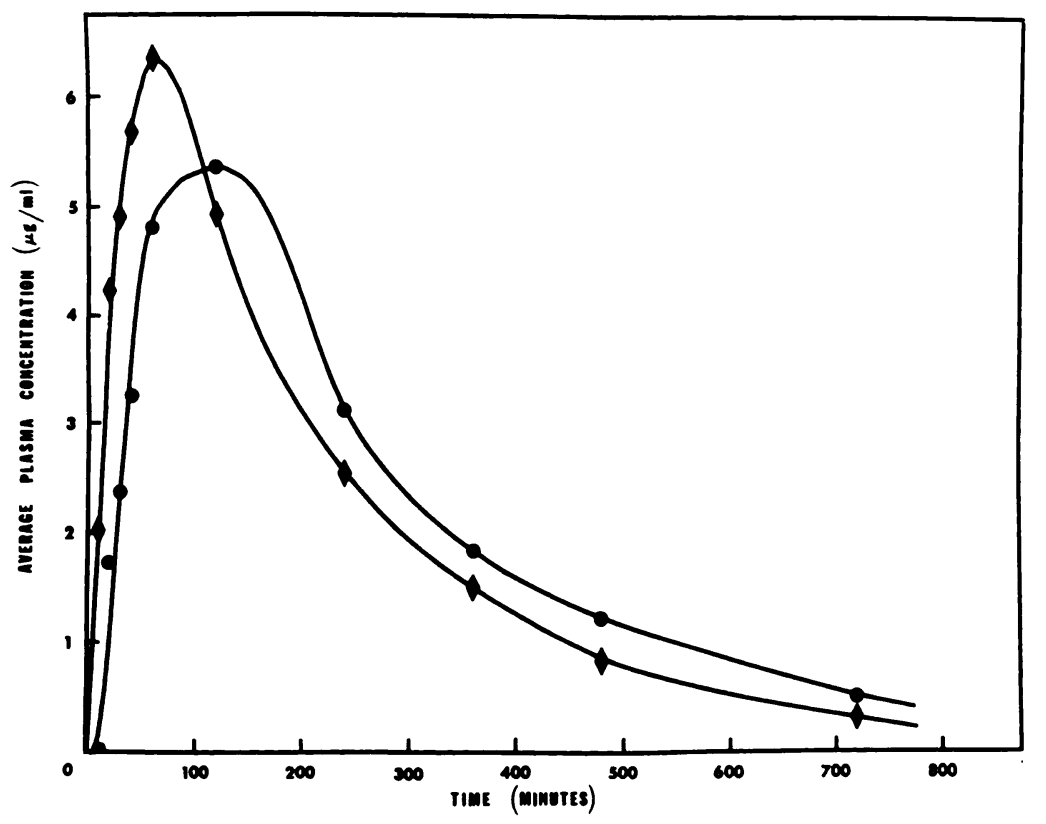

Fig. 1. Mean acetaminophen plasma levels for ten subjects following a single 650-mg oral dose: ( $)$ ) treatment $A$ (soft gelatin capvule); ( $)$ treatment $B$ (commercial tablet).

dosing. Urine collections were made in the following time intervals: predose, 0-2 hours, 2-4 hours, 4-6 hours, 6-8 hours, 8-12 hours, 12-24 hours. The urine samples were collected in plastic bottles without addition of any preservative. After collection, the urine volumes were measured, the urine was quick-frozen, and kept in the frozen state until just prior to assay. A modification of the analytical procedure of Conklin and Hollifield ${ }^{8}$ was used to assay for nitrofurantoin in plasma and urine samples. (Conklin and Hollifield employed $1 \mathrm{ml}$ urine, $4 \mathrm{ml} 0.1 M \mathrm{HCl}$, and 10 $\mathrm{ml}$ nitromethane. In the present study 2 $\mathrm{ml}$ urine, two drops concentrated $\mathrm{HCl}$, and $4 \mathrm{ml}$ nitromethane were used.)

Each blood sample from both studies was drawn into one Vacutainer tube containing heparin as anticoagulant and the tubes were treated as described previously. ${ }^{\circ}$ The treatment schedules for both studies are outlined in Table I.

\section{Results}

Acetaminophen. Table II summarizes average plasma concentrations and 24hour urinary excretion data for treatments $A$ and $B$ and includes a summary of results of the analyses of variance. Figure 1 depicts graphically these average plasma levels. Inspection of the table indicates that since no significant differences in total average amounts of unchanged drug excreted in the urine and in average areas under the plasma concentration curves following the two treatments were obtained, no significant differences in bioavailability between the two treatments existed. However, Table II also shows that average plasma concentrations of acetaminophen at $10,40,60,240,360,480$, and 720 minutes differed significantly. This suggests that the rates of absorption were, on the average, significantly different following the two dosage forms. Figure 1 reveals that the peak average plasma 
concentration following treatment $\mathbf{A}$ appeared at about 120 minutes, while that for treatment $B$ appeared at about 60 minutes; this is consistent with the hypothesis that acetaminophen in treatment B (the commercial tablet) was more rapidly absorbed than acetaminophen in treatment A (the soft gelatin capsule).

Nitrofurantoin. Figure 2 depicts the average plasma levels obtained after oral administration of nitrofurantoin. Figure 3 summarizes the average urinary excretion data. A summary from the analyses of variance appears in tabular form in Tables III and IV. Since no significant differences between mean treatment areas and in amounts of unchanged drug excreted in the urine were obtained for the two dosage forms tested, their bioavailabilities

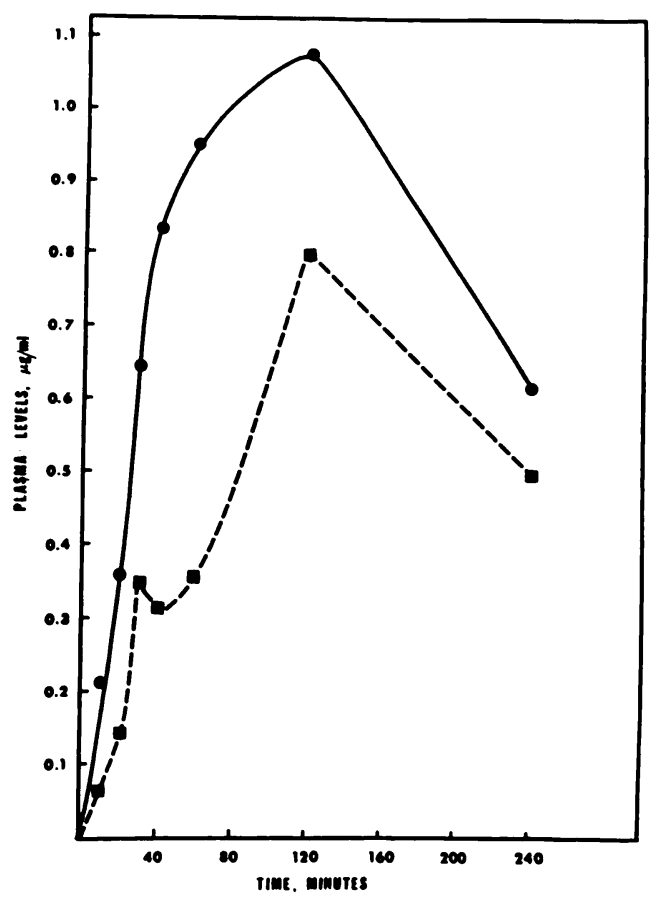

Fig. 2. Mean nitrofurantoin plasma levels for ten subjects follouing a single 100-mg oral dose: ( ) treatment $A$ (soft gelatin capsule); (-D.) treatment $B$ (commercial tablet). were considered to be equivalent. However, the plasma level data suggest that the drug was absorbed more rapidly following administration of the soft gelatin capsule than following the commercial tablet. Table III supports this by showing that the differences between average plasma concentrations at 20,40 , and 60 minutes, as well as the difference between average peak plasma concentrations, were significant.

\section{Discussion}

The total amount of unchanged drug excreted in the urine and the total area under the plasma concentration curve are generally accepted as measures of relative efficiency of absorption. No significant differences were shown for either of these parameters following the two treatments in both studies. However, for nitrofurantoin, the area difference gave a significance level between 0.10 and 0.05 (Table III). This fact coupled with the alternate significant-not significant pattern displayed in Table III suggests that if more subjects had been used, the plasma level nonequivalency might have been significant at all sampling times to 120 minutes as well as the area under the curve. This is supported by the large coefficients of variation calculated from the residual mean square at each sampling time, which are measures of intrasubject variation, assay error, and unknown sources of variation.

The time taken for a drug to attain peak concentration is also a reflection of the rate of absorption. For acetaminophen, the difference between the mean times of individual subjects to attain peak concentration was not significant. However, as seen in Table II, the mean times of 84 and 58 minutes for treatment $A$ and $B$, respectively, gave a significance level between 0.05 and 0.10 ; interpolation gave $P=0.07$, which is a borderline level. Inspection of Fig. 1, coupled with the observation that

The Journal of Clinical Pharmacology 


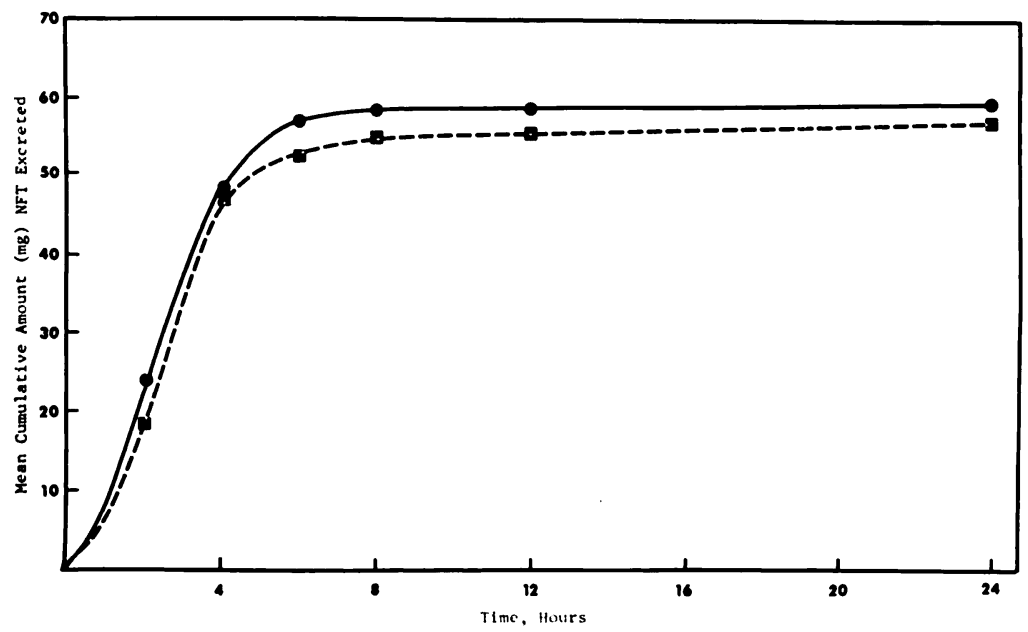

Fig. 3. Mean cumulative amount ( $\mathrm{mg}$ ) of nitrofurantoin excreted for ten subjects following a single 100-mg oral dose: (- ) treatment $A$ (soft gelatin capsule); ( $-1-$ ) treatment $B$ (commercial tablet).

statistically significant differences were obtained between treatment means at all sampling times after the curves intersect (about 110 minutes), is strong evidence that, indeed, the commercial tablet (treatment B) was more rapidly absorbed than the soft gelatin capsule (treatment $\mathbf{A}$ ). For nitrofurantoin, it was difficult to the urinary excretion data (Table IV) assign a value for the time of maximum plasma level owing to the noncontinuous appearance of the individual subject plasma curves. Irregular concentration profiles occurred for subjects $2,3,4,5$, 7,8 , and 10.

A discrepancy appears to exist between

\section{TABLE IV}

Summary of the Average Cumulative Amount of Nitrofurantoin Excreted by Ten Normal Subjects Following a Single 100-mg Oral Dose of Nitrofurantoin

\begin{tabular}{|c|c|c|c|c|}
\hline \multirow[b]{2}{*}{$\begin{array}{l}\text { Time interval } \\
(\mathbf{h r})\end{array}$} & \multicolumn{2}{|c|}{$\begin{array}{l}\text { Cumulative amount excreted } \\
\text { (mg) }\end{array}$} & \multirow[b]{2}{*}{$\begin{array}{l}\text { Significance level of } \\
\text { difference between } \\
\text { treatment averages } \\
\text { from ANOVA }\end{array}$} & \multirow{2}{*}{$\begin{array}{l}\text { C.V. }(\%) \\
\text { from } \\
\text { residual } \\
\text { mean square }\end{array}$} \\
\hline & $\begin{array}{l}\text { Treatment A } \\
\text { (soft gelatin } \\
\text { capsule) }\end{array}$ & $\begin{array}{l}\text { Treatment B } \\
\text { (commercial } \\
\text { tablet) }\end{array}$ & & \\
\hline $0-2$ & 23.8 & 18.3 & n.s. $(0.25>P>0.10)$ & 41.7 \\
\hline $0-4$ & 48.8 & 47.5 & n.s. $(P>0.25)$ & 40.9 \\
\hline $0-6$ & 57.6 & 53.2 & n.s. $(P>0.25)$ & 28.2 \\
\hline $0-8$ & 58.7 & 55.3 & n.s. $(P>0.25)$ & 25.3 \\
\hline $0-12$ & 59.1 & 55.8 & n.s. $(P>0.25)$ & 25.0 \\
\hline $0-24$ & 59.2 & 56.7 & n.s. $(P>0.25)$ & 24.9 \\
\hline
\end{tabular}


and plasma level data (Table III) in the nitrofurantoin study. The treatment means of the cumulative amounts of nitrofurantoin excreted in the urine did not differ significantly at any time, whereas some differences between treatment average plasma concentrations were significant up to 60 minutes. This type of discrepancy between urinary excretion data and plasma data is difficult to explain, but an almost identical type of disparity was reported by Langlois et al..$^{\circ}$ in a bioavailability study of a sulfamethazole combination. A plausible explanation based upon sampling times seems most reasonable. All the statistically significant differences in average plasma level occurred in the first 60 minutes, while the first urine collection time interval was 0 to 120 minutes. Apparently, urine was not collected at frequent enough time intervals to demonstrate differences that were readily delineated by plasma levels.

\section{Summary}

In two test panels of ten subjects each, plasma levels and urinary excretion of two drugs, acetaminophen and nitrofurantoin, were measured in order to compare bioavailabilities when the drugs were formulated as commercial tablets and as specially formulated gelatin capsules. No significant differences in relative efficiency of absorption were obtained between tablets and capsules with either drug. However, when comparing rates of absorption, the soft gelatin capsule appeared slightly superior to the tablet in the nitro- furantoin study, whereas it appeared slightly inferior to the tablet in the acetaminophen study. The differences were not striking with either drug.

\section{References}

1. Wagner, J. G.: Biopharmaceutics and Relevant Pharmacokinetics. Drug Intelligence Publications, Hamilton, Illinois, 1971.

2. Gwilt, J. R., Robertson, A., Goldman, L., and Blanchard, A. W.: The absorption characteristics of paracetamol tablets in man. J. Pharm. Pharmaool. 15:445 (1963).

3. McGilveray, I. J., Mattok, G. L., Fooks, J. R., Jordan, N., and Cook, D.: Acetaminophen. II. A comparison of the physiological availabilities of different commercial dosage forms. Can. J. Pharm. Sci. 6:38 (1971).

4. Mattok, G. L., Hossie, R. D., and McGilveray, I. J.: In vivo:in vitro studies of nitrofurantoin tablets. Ibid. 7:84 (1972).

5. Hom, F. S., and Miskel, J. J.: Oral dosage form design and its influence on dissolution rates for a series of drugs. J. Pharm. Sci. 59:827 (1970).

6. Wagner, J. G., Welling, P. G., Lee, K. P., and Walker, J. E.: In vivo and in vitro availability of commercial Warfarin tablets. J. Pharm. Sci. 60:666 (1971).

7. Kostenbauder, H. B.: University of Kentucky, Lexington, Kentucky, personal com. munication.

8. Conklin, J. D., and Hollifield, R. D.: A new method for the determination of nitrofurantoin in urine. Clin. Chem. 11:925 (1965).

9. Langlois, Y., Gagnon, M. A., and Tetreault, L.: A bioavailability study on three oral preparations of the combination trimethoprim-sulfamethazole. J. Clin. Pharmacol. 12:196 (1972).

Please address reprint requests to: Dr. John G. Wagner, Upjohn Center for Clinical Pharmacology, The University of Michigan, Ann Arbor, Mich. 48104. 